\title{
Formação inicial de professores de geografia: entre expectativa e realidade a ação do PIBID
}

\author{
Introducing training of geography's teachers: the pibid action between \\ spectation and reality \\ Formación inicial de profesores de geografía y la acción del pibid: entre \\ expectativa y realidad
}

\author{
Michael Wellington Sene ${ }^{1}$ \\ Marquiana de Freitas Vilas Boas Gomes ${ }^{2}$
}

Recebido em 04/2017 - aceito em 07/2017.

\begin{abstract}
RESUMO: A profissão docente é complexa, pois integra produção do conhecimento e relações humanas. Estas relações implicam ao docente construir um conjunto de estratégias que não se restrinjam apenas a contribuir com o desenvolvimento cognitivo do estudante, mas também, envolver-se em uma trama de dimensões culturais, sociais e psicológicas próprias do interagir com o outro. Discutir as dificuldades e potencialidades da formação de professores se faz necessário, tendo em vista que estes profissionais são responsáveis por boa parte da melhoria na qualidade da educação. É neste contexto, que este trabalho visa discutir o processo de formação docente a partir de projetos colaborativos entre universidade e escola, analisar as contribuições e limites da formação inicial aliada ao PIBID e os Novos Talentos, ambos financiados pela CAPES. Nele, analisa-se como o PIBID e os Novos Talentos estão sendo inseridos no curso de formação inicial de professores de Geografia da Universidade Estadual do Centro-Oeste - UNICENTRO, campus CEDETEG, localizado na cidade de Guarapuava-PR. Para isso, utilizar-se-á a metodologia da pesquisa participante. Apresentam-se aqui alguns resultados alcançados a partir da pesquisa realizada com alunos (pibidianos e não pibidianos) da quarta série do curso de licenciatura em Geografia, e de observações realizadas no PIBID e na implementação dos Novos Talentos, com as quais foi possível analisar as contribuições destes programas para a formação profissional docente. A pesquisa realizada evidenciou que ambos os programas têm sido fundamentais para a formação inicial e continuada de professores, sobretudo pela troca de experiências entre universidade e escola.
\end{abstract}

Palavras-Chave: Formação Inicial, Profissionalidade Docente, Projetos Colaborativos.

ABSTRACT: The teacher profession is complex, because it integrates knowledge production and human relations. These relations imply to the teacher to create a set of strategies that not be restrict only to contribute with the student's cognitive development, but also, that involve him/her in a network of cultural, social and psychological dimensions specifics of the interaction with the other. Discuss the difficulties and potentialities of the teacher training are necessary, in order to that these professionals are responsible for a big contribution to the education quality improvement. It is, in this context, that this work aims to discuss the teacher training process from collaborative processes between university and school, to analyze the contributions and limits of the introducing training allied to two projects, Programa Institucional de Bolsas de Iniciação à Docência (PIBID) [Institutional Program of Introduction to Teaching] and to the Novos Talentos [New Talents], both them funded by CAPES (Coordenação de aperfeiçoamento de Pessoal de Nivel Superior [Coordination for the Improvement of Higher Education Personnel]. In it, is analyzed how the PIBID and the Novos Talentos are being inserted in the teachers geography initial training course of the Universidade Estadual do Centro Oeste (UNICENTRO) [State University of the Center West], CEDETEG Campus (Campus do Centro de Desenvolvimento Tecnológico de Guarapuava) [Campus of the Technological Development Center of Guarapuava], that is located in Guarapuava, state of Paraná, Brazil. To this end, the participative research methodology will be used. Some reached results are showed here from the survey make with 4th grade students (PIBID project integrants or not) that are taking major

Geografia (Londrina) v. 26. n. 1, p. $118-130$, jan/jun, 2017. 
in geography teaching, about the observations made at PIBID and in the implementation of the Novos Talentos, which were possible to analyze the contributions from these programs to the teaching professional training. The research that was made highlighted that both the two programs have been fundamental for the teachers' introducing continuous training, especially through the change of experiences between university and school.

Keywords: introducing teaching; profissionalidade [degree of professionalism], collaborative projects.

RESUMEN: La profesión docente es compleja, pues integra la producción del conocimiento y las relaciones humanas. Esas relaciones implican al docente construir un conjunto de estrategias que no si restrinjan apenas a contribuir con el desarrollo cognitivo del estudiante, más también, envolverse en una trama de dimensiones culturales, sociales y psicológicas propias de la interacción con el otro. Discutir las dificultades y potencialidades de la formación de profesores se hace necesario, teniendo en cuenta que eses profesionales son responsables por buena parte de la mejoría en la cualidad de la educación. Así, es en ese contexto, que ese trabajo visa discutir el proceso de formación docente a partir de proyectos colaborativos entre la universidad y escuela, también analizar las contribuciones y límites de la formación inicial aliada al PIBID y los Nuevos Talentos, ambos financiados por la CAPES. En ese, si analiza como el PIBID y los Nuevos Talentos están siendo inseridos en el curso de formación inicial de profesores de Geografía de la Universidade Estadual do Centro-Oeste - UNICENTRO, campus CEDETEG, imbricado en la ciudad de Guarapuava-PR. Para eso, va utilizarse de la metodología de la pesquisa participante. Si presenta acá algunos resultados que obtuvieron a partir de la pesquisa realizada con alumnos (pibidianos y no pibidianos) del cuarto año del curso de licenciatura en Geografía, y de observaciones realizadas en el PIBID y en la implementación de los Nuevos Talentos, con las cuales fue posible analizar las contribuciones de eses programas para la formación profesional docente. La investigación realizada evidenció que ambos los programas tienen sido fundamentales para la formación inicial y continuada de los profesores, sobre todo por el cambio de experiencias entre la universidad y la escuela.

Palabras clave: formación inicial, profesión docente, proyectos colaborativos.

\section{INTRODUÇÃO}

Este trabalho é parte da pesquisa de mestrado, no qual foram discutidas as contribuições do Programa Institucional de Iniciação à Docência (PIBID) na formação inicial de professores de Geografia no Estado do Paraná. Partindo desse pressuposto, neste trabalho discutir-se-á e analisar-se-á como se estabelece a formação inicial, ponderando as contribuições do PIBID e do programa Novos Talentos para os acadêmicos do curso de Geografia da UNICENTRO.

Para discutir acerca da temática proposta, inicialmente parte-se do debate sobre o que se considera como docência, ou seja, "se constitui em um conjunto de ações/intervenções que favorecem ao discente a compreensão da realidade de seu entorno e, consequentemente, a ampliação da sua visão de mundo" (SARTORI, 2011, p. 4). Logo, a formação de um docente não se limita a garantir o domínio do conhecimento disciplinar, mas de envolvê-lo em um processo que compreenda a dimensão complexa de sua profissão. Trata-se não só da disciplina da qual é responsável, mas de uma consciência do mundo para a formação de um cidadão que nele atuará. 
Na maioria das universidades e faculdades brasileiras a formação do professor, integra disciplina específica e pedagógicas. Neste aspecto, foi com as Diretrizes Curriculares Nacionais em 2002, que a alteração do sistema de formação de professores, conhecido como sistema $3+1$, ou seja, três anos com disciplinas específicas e um ano com disciplinas pedagógicas, foi alterado para a inclusão de mais horas de estágio e prática de ensino e, também, da inserção do acadêmico no ambiente escolar já nas primeiras séries do curso de formação.

Porém, substancialmente pouco tem se alterado quanto ao modelo da formação (AZEVEDO et al, 2012). As mudanças foram substantivas do ponto de vista quantitativo, com 400 horas de estágio supervisionado somadas a 400 horas de práticas de ensino, porém, do ponto de vista qualitativo, ainda não se têm um diagnóstico se estas alterações refletiram na melhoria da formação.

A proposta das Diretrizes Curriculares Nacionais (2002) visa incorporar a discussão pedagógica já nas séries iniciais dos cursos de licenciatura, e com isso, provocar um debate interno sobre a formação de professores. De fato, sua incorporação promoveu o debate, contudo, no lugar de uma ampla revisão da formação, em muitas estruturas curriculares, foi sendo incorporado o conteúdo pedagógico no âmbito das disciplinas curriculares específicas, como forma de agregar o quantitativo exigido, sem necessariamente alterar-se a prática. Mello (2000), ao discutir o processo de formação de professores afirma que os cursos de formação de professores:

[...] são ministrados num contexto institucional distante da preocupação com a educação básica, que não facilita nem mesmo a convivência com pessoas e instituições que conhecem a problemática desta última. Os professores formadores que atuam nesses cursos, quando estão em instituições de qualidade, são mais preocupados com suas investigações do que com o ensino em geral, e menos interessados ainda no ensino da educação básica. (MELLO, 2000, p. 100).

O autor ainda analisa esta formação, no contexto da relação teoria e prática, associando-a, ao conceito de competência. Para ele:

[...] competência se constrói em situação; não é "conhecimento de", muito menos "conhecimento sobre", mas é conhecimento que pode ser mobilizado para agir e tomar decisões em situações concretas. Situações da vida real envolvem sempre um componente imponderável e imprevisível. No ensino, isso é mais do que verdadeiro. (MELLO, 2000, p. 104).

Diante do exposto, concorda-se com Azevedo et al (2012) quando afirmam que: "a formação de professores não pode ser pensada, desvinculada do espaço real em que se efetiva o seu campo prioritário de atuação profissional, ou seja, a escola" 
(AZEVEDO et al, 2012, p.1014). Mas também defende que esta prática na escola esteja alicerçada de uma boa fundamentação teórica.

Conforme já citado, e levando em consideração os apontamentos propostos por estes autores, pode-se afirmar que os cursos de licenciatura quando poucos articulam a teoria e a prática, tornam a formação dos futuros professores limitada. É neste contexto de preocupação com a formação de professores, que estão os novos programas institucionais financiados pela CAPES, os quais têm provocado o debate e colocado no centro à formação docente enquanto pratica profissional. Dentre eles, destacam-se o PIBID e o Programa Novos Talentos. Incentiva-se por meio destas iniciativas, a necessária articulação teoria-pratica já prevista na Lei de Diretrizes e Bases da Educação Nacional (LDB) 9.394/96. De acordo com a CAPES dentre os objetivos do PIBID têm-se:

[...] c) Elevar a qualidade da formação inicial de professores nos cursos de licenciatura, promovendo a integração entre a Educação Superior e Educação Básica; d) inserir os licenciandos no cotidiano de escolas da rede pública de educação, proporcionando-lhes oportunidades de criação e participação em experiências metodológicas, tecnológicas e práticas docentes de caráter inovador e interdisciplinar que busquem a superação de problemas identificados no processo de ensino-aprendizagem; e) incentivar escolas públicas de educação básica, mobilizando seus professores como co-formadores dos futuros docentes e tornando-as protagonistas nos processos de formação inicial para o magistério; f) e contribuir para a articulação entre teoria e prática necessárias à formação dos docentes, elevando a qualidade das ações acadêmicas nos cursos de licenciatura. (BRASIL, 2010, p. 3) (Grifo nosso).

O PIBID integra o acadêmico à realidade do seu futuro local de trabalho, possibilitando que estes conheçam o ambiente escolar, mas que também realizem intervenções pedagógicas e inovem as propostas dos professores supervisores. Aliado ao contato com a docência, o acadêmico tem neste programa, a contribuição significativa para sua profissionalização. Pois, assim como o estágio, o PIBID se apresenta como um "divisor de águas" no encontro entre a expectativa do acadêmico com relação à sua atuação profissional, e a realidade vivenciada na escola.

Até pouco tempo, podia-se facilmente observar que após o contato com a escola no estágio supervisionado, alguns acadêmicos acabavam por abandonar o curso, por perceber que não era aquilo que se buscava profissionalmente. Ou finalizava a formação, mas não exercia a profissão. Programas como o PIBID reduzem este choque e contribuem para reduzir a evasão dos cursos de licenciatura e a qualificação do futuro docente. Contribui também para a desconstrução do mito da escola ideal e do aluno ideal, para a realidade da situação de trabalho docente, na 
qual a escola é viva, com sua complexidade e contradições e os alunos são sujeitos sociais, condicionados historicamente, e ávidos por um ser e estar no mundo, mesmo quando a escola não se apresenta para ele um tempo-espaço significante.

De acordo com a Coordenação de Aperfeiçoamento de Pessoal de Nível Superior - CAPES, o PIBID:

[...] se diferencia do Estágio Supervisionado por ser uma proposta extracurricular, com carga horária maior que a estabelecida pelo Conselho Nacional de Educação - CNE para o estágio e por acolher bolsistas desde o primeiro semestre letivo, se assim definirem as IES em seu projeto. A inserção no cotidiano das escolas deve ser orgânica e não de caráter de observação, como muitas vezes acontece no estágio. A vivência de múltiplos aspectos pedagógicos das escolas é essencial ao bolsista (BRASIL, 2009-2011, p. 30).

O PIBID, além de facilitar essa aproximação teoria e prática, traz também aos alunos participantes a oportunidade de preencher as lacunas consequentes da formação inicial. Seja nos aspectos conceituais, e nesse caso dos conceitos chave da Geografia, como Espaço, Região, Território, Paisagem, Redes, Escala, Lugar, Ambiente, entre outros, ou nos aspectos técnicos da prática docente, como o preparo das atividades, operacionalização das aulas, domínio de turma, transposição didática, entre outros.

Outro programa de formação de professores financiado pela CAPES é o Novos Talentos, seu objetivo é apoiar propostas para realização de atividades extracurriculares para professores e alunos da educação básica - tais como cursos, oficinas ou equivalentes - que ocorram no período de férias das escolas públicas e/ou em horário que não interfira na frequência escolar. As atividades deste programa visam o aprimoramento e a atualização do público-alvo e a melhoria do ensino de ciências nas escolas públicas do país.

No caso do projeto realizado pela UNICENTRO, no curso de Geografia, as ações integram atividades dos Novos Talentos com o PIBID e o estágio supervisionado, na concepção de rede, ou seja, articula-se formação inicial e continuada, estabelecendo a aproximação entre os professores em formação e os professores da escola, sob a orientação dos professores da Universidade.

Neste contexto, entende-se que a formação inicial e a atividade profissional docente são processos articulados. Assim, propõe-se políticas e projetos que deem suporte a formação inicial tendo como base parceria entre instituições formadoras e a escola. Sobre ações desta natureza Ambrosetti et al (2013) afirma que "ainda que não configure uma reestruturação dos modelos de formação, pode trazer avanços no sentido de promover maior articulação entre os espaços e tempos nos percursos formativos dos professores" (AMBROSETTI et al, 2013, p.157). É neste sentido, que 
neste trabalho, problematizam-se as atividades envolvendo o PIBID e Novos Talentos, a fim de compreender as contribuições destes para a formação inicial.

\section{METODOLOGIA}

Tendo como proposta analisar e compreender projetos de colaboração entre universidade e escola, sobretudo a formação de professores, é indispensável estar inserido nesse processo para que se conheçam como estes se dão e, a partir daí, sejam apontados seus limites e potencialidades, acompanhando as atividades de planejamento e execução das atividades do PIBID e dos Novos Talentos nas escolas e na Universidade.

Para isso, a metodologia utilizada é a Pesquisa Participante. Através da Pesquisa Participante, acompanhamos todas as ações dos dois programas, no âmbito do curso de Geografia da Universidade Estadual do Centro-Oeste, UNICENTRO, no campus CEDETEG. De acordo com Brandão (1984), a pesquisa participante "trata-se de um enfoque de investigação social por meio do qual se busca plena participação da comunidade na análise de sua própria realidade, com o objetivo de promover a participação social para o benefício dos participantes da investigação". Santos (2011) colabora com a definição desse tipo de pesquisa, para ele a Pesquisa Participante:

[...]A pesquisa será feita com o envolvimento do sujeito-objeto. $O$ pesquisador não só passa a ser objeto de estudo, assim como os sujeitos-objetos são igualmente pesquisadores onde todos, pesquisador e pesquisados, identificam os problemas, buscam-se conhecer o que já é conhecido a respeito do problema, discutem as possíveis soluções e partem para a ação (SANTOS, 2011, p. 2-3).

Com esse tipo de pesquisa e com o intuito de compreender se existe contribuição do PIBID ao processo de formação inicial de professores de Geografia, tem sido realizado observações sistemáticas das ações no período de 2013 a 2016, bem como a aplicação de um instrumento de coleta de dados (questionário) para os acadêmicos do curso de Geografia Licenciatura.

Com vista a conhecer o perfil dos sujeitos da pesquisa, também foi aplicado um instrumento piloto (na forma de questionário) para os alunos da quarta série do curso de Geografia Licenciatura da UNICENTRO. A quarta série foi escolhida por já estarem saindo do curso e passado por todas as disciplinas de Estágio Supervisionado. O questionário foi aplicado à metade dos alunos dessa série e dentre eles cinco fazem parte do PIBID disciplinar de geografia e um integrante do PIBID Interdisciplinar. $O$ PIBID Interdisciplinar está na sua primeira edição e é integrado aos cursos de Letras, História e Biologia da mesma universidade. 
O questionário continha questões abertas e fechadas. As perguntas buscaram verificar: se participaram durante a graduação de programa de ensino, pesquisa ou extensão, se depois de formado o licenciado pretendia atuar como professor, além de saber quais as principais dificuldades e facilidades com temas e práticas pedagógicas relacionadas à prática docente. Além desta enquete, sistematizou-se as observações realizadas no âmbito do PIBID e do Programa Novos Talentos, com vistas a apresentar as contribuições e os limites destes para a formação dos acadêmicos na licenciatura em Geografia.

\section{RESULTADOS E DISCUSSÃO}

\section{Perfil dos Sujeitos de Pesquisa}

Como já mencionado foram aplicados questionários para $50 \%$ dos alunos regulares do curso de Geografia Licenciatura, dentre os quais cinco participam do PIBID disciplinar de Geografia e um do PIBID interdisciplinar e todos, participaram, pelo menos de uma ação do programa Novos Talentos.

Sobre a atuação como professor, $88 \%$ dos sujeitos participantes da pesquisa, responderam que pretendem atuar como professores e, $12 \%$ que não desejam assumir essa profissão. Os que responderam negativamente a essa questão, justificaram que se utilizaram do diploma para fazer concursos de nível superior ou apenas pelo diploma, ou seja, não se identificaram com a profissão. Já os que pretendem atuar, afirmaram gostar da profissão e por ser uma profissão digna. Vale ressaltar uma justificativa de um pibidiano, bastante interessante: "Tive a oportunidade de ter algumas experiências em sala de aula, como o PIBID, das quais confirmaram minha futura atuação na docência" Respondente 15.

Sobre o estágio o Estágio Supervisionado para a vida profissional do professor de Geografia, apenas 6\% não consideram importante (Gráfico 1). Os 6\% que consideraram "pouco importante" são os mesmos que não pretendem atuar como professores após formados. Sobre a carga horária de estágio, 59\% não consideram a carga horaria suficiente para que se tenha uma noção da vida profissional do professor de Geografia. Uma das justificativas foi que "[...] esse pouco tempo não possibilita uma visão total do que é ser professor, de vivenciar, de estabelecer relações com a escola e com os alunos", Respondente 16. Os demais, julgaram o tempo suficiente. 


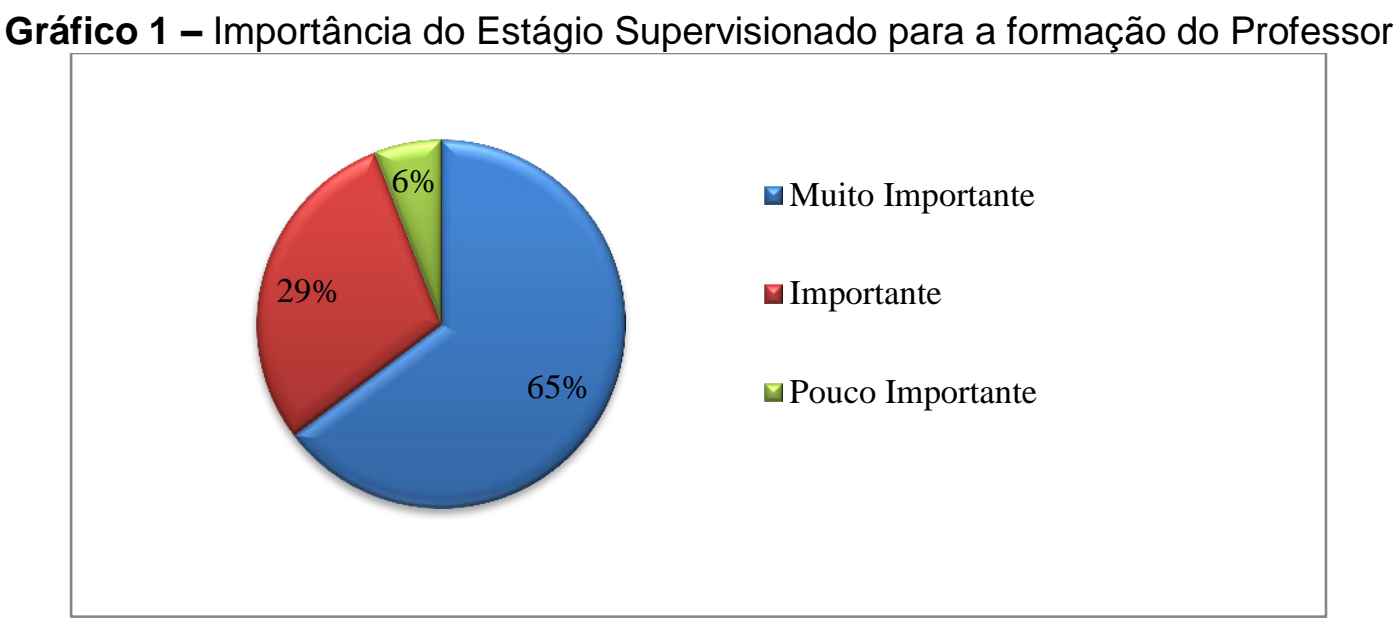

Fonte: Pesquisa de Campo realizada pelos autores (2016).

Gráfico 2 - Opinião dos acadêmicos sobre a adequação da carga horária do Estagio Supervisionado à Formação do Professor

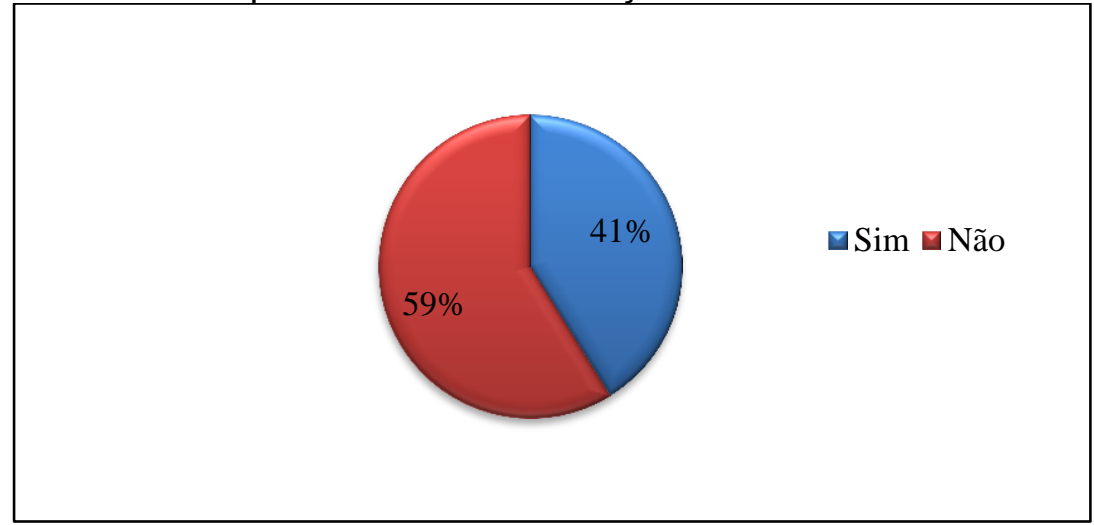

Fonte: Pesquisa de Campo realizada pelos autores (2016).

Sobre os conteúdos geográficos que os acadêmicos, participantes da pesquisa, sentem maior dificuldade, destaca-se aqueles relacionados a Cartografia, Geografia Física e Epistemologia da Geografia (tabela 01).

Tabela 1 - Conteúdos Geográficos que os atores sentem mais dificuldade

\begin{tabular}{l|c}
\hline \multicolumn{1}{c|}{ Conteúdo } & $\%$ por resposta* \\
\hline Conceitos (Espaço, paisagem, região, etc.) & $12 \%$ \\
\hline Cartografia & $47 \%$ \\
\hline Geografia Física & $41 \%$ \\
\hline Geografia Humana & $12 \%$ \\
\hline Epistemologia da Geografia & $41 \%$ \\
\hline Não sente Dificuldade & $6 \%$ \\
\hline
\end{tabular}

${ }^{*}$ A pergunta era de múltipla escolha, sendo considerada a frequência das respostas.

Fonte: Pesquisa de Campo realizada pelos autores (2016). 
No campo da Geografia Física, os acadêmicos citaram as diferentes temáticas a ela relacionadas - geologia, geomorfologia, processos geológicos, hidrologia, climatologia, entre outras. A principal justificativa é a lacuna deixada durante o curso de graduação nessas áreas. Partindo desse resultado, concordamos com Mello (2000) quando afirma que: "[...] Ninguém facilita o desenvolvimento daquilo que não teve a oportunidade de aprimorar em si mesmo. Ninguém promove a aprendizagem de conteúdos que não domina a constituição de significados que não compreende nem a autonomia que não pôde construir [...]" (MELLO, 2000, p. 102).

Quando se trata das competências pedagógicas de um professor de Geografia é possível perceber através da pesquisa, que alunos participantes do PIBID se consideram aptos para a maioria das alternativas apresentadas, sendo elas: Plano de Aula, Elaboração de Atividades, Domínio de Turma, Preenchimento do Livro de Classe, Avaliação, Transposição Didática, Preparo das Aulas e Plano de Trabalho Docente. Mas tais competências não são exclusivas dos pibidianos, a maioria dos graduandos se considera apto a realizar essas atividades. No entanto, o Plano de Trabalho Docente foi o menos preenchido, com apenas $24 \%$, onde todos os que responderam já atuam como professores.

\title{
SOBRE A CONTRIBUIÇÃO DO PIBID NA FORMAÇÃO PROFISSIONAL
}

Para analisar a contribuição do PIBID na formação profissional, nos valemos do depoimento dos pibidianos que atuaram no programa em 2013, sendo que parte deles, permanecem em 2014. Sobre isso, destacamos depoimentos:

\begin{abstract}
O PIBID traz para o acadêmico de licenciatura a vivencia em sala de aula. Temos a oportunidade de realizar metodologias no ensino de geografia, debater questões sobre o mesmo, interagir com os coordenadores e, principalmente, o convívio no âmbito escolar. [...]. "Com isso, ganhamos experiência na universidade como exercer a profissão de professor" (bolsista do Pibid 01).

[...] com o desenvolver das atividades, nós acadêmicos, ganhamos mais habilidades e experiências para exercer nossa futura profissão. Com o trabalho em grupo podemos perceber não só um crescimento profissional, mas também pessoal, em função do maior contato com a comunidade escolar, professores da universidade e colegas do curso" (bolsista do Pibid,02).
\end{abstract}

Como observamos nos depoimentos, o PIBID se apresenta para os bolsistas como uma possibilidade a mais de vivência na escola que agrega a sua formação maiores habilidades, segurança, e envolvimento com o universo de sua profissão.

Esta contribuição, porém, não está circunscrita ao bolsista acadêmico, mas também envolve o professor supervisor. Nos depoimentos isto fica evidente:

Estou participando do Programa Institucional de Bolsa de Iniciação a Docência, aproximadamente há um ano, consigo ter claro que este 
programa tem um papel fundamental na formação do futuro professor, mesmo em um curto tempo. São inúmeros os aspectos que são possíveis levantar nesse sentido. A visão prévia do acadêmico que vai muito além do trabalho do estágio supervisionado, pois, muitas vezes, o acadêmico desenvolve o estágio mais por um motivo de necessidade da aprovação da disciplina do que seu próprio aprendizado. Na participação nesse programa, o objetivo é mesmo a capacitação e o aprendizado. Para a escola que recebe o programa, existe uma verdadeira revolução, pois os alunos em sala de aula se sentem valorizados e motivados, devido ao fato de um acadêmico, figura muitas vezes distante da realidade da escola do campo, estar tão próximo de sua realidade, tornando a Universidade, antes distante, um fato presente e possível de ser alcançada (Professor Supervisor do PIBID).

É interessante notar que os supervisores encontram no PIBID um apoio e revitalização da prática escolar, bem como uma aproximação do professor com a universidade, um diálogo que permite aos dois sujeitos, professor e acadêmico o enriquecimento e complementaridade na formação.

Os coordenadores do PIBID também atestam esta contribuição, conforme o depoimento a seguir:

O PIBID é um programa muito importante para formação inicial, pelo envolvimento e integração efetiva da universidade com a escola, mas também para a formação continuada, pois o professor supervisor tem acesso a um conjunto de discussões teórico-metodológicas sobre a sua área de atuação e, assim, tem a oportunidade de refletir e, quando necessário, transformar sua prática docente. Portanto, tratase de uma política pública que redimensiona as licenciaturas, seja por permitir que o cotidiano da escola seja pautado dentro e fora da sala de aula, seja por meio das discussões teóricas e das experiências vivenciadas na universidade e na escola. Aos docentes da universidade, formadores de professores, é um programa que contribui para que velhas e novas discussões sobre o ensino sejam tratadas a luz de um projeto colaborativo, diminuindo as distâncias entre as instituições e, sobretudo, unindo os diferentes níveis de ensino em prol da melhoria e da transformação da educação. Com o Pibid, reduzem-se às dificuldades de definir quais são os temas, metodologias, conceitos mais importantes para o licenciado, no contexto da sua formação e da realidade escolar, uma vez que no diálogo com a escola, estas questões fluem naturalmente, fazendo com que o currículo universitário seja problematizado e até mesmo revisto (Coordenação do PIBID Geografia).

\section{PROGRAMA NOVOS TALENTOS E A FORMAÇÃO DE PROFESSORES}

As considerações que trazemos aqui para o texto, diz respeito a avaliação de ações no âmbito do programa Novos Talentos, no segundo semestre de 2013, com os acadêmicos do estágio supervisionado da quarta série, do curso de Geografia Licenciatura, UNICENTRO.

Trata-se de oficinas que integraram ações do estágio com as do Programa, cuja temática teve como foco a educação ambiental, com ênfase na questão das águas. Nestas ações, os acadêmicos foram incentivados a pesquisar sobre o tema e 
preparar ações lúdicas, as quais realizaram com alunos do ensino médio, em uma escola pública na cidade Guarapuava. Ao final das ações, foi realizada uma avaliação com vistas a discutir coletivamente os resultados positivos e negativos do processo educativo empreendido na escola.

Quanto aos pontos positivos, os acadêmicos destacaram: o desenvolvimento dos trabalhos em grupo, possibilitando a discussão nos mais variados pontos, à divisão da responsabilidade na busca de materiais, na construção de conteúdos e na resolução das dificuldades na sala de aula. Outro destaque foi para a forma inovadora proposta nas oficinas, as quais tornaram a aula mais interessante ao aluno da escola. A qualidade e autonomia que tiveram na definição do tema, preparação e execução dos materiais foram fundamentais aos acadêmicos. Ainda um aspecto importante evidenciado no desenvolvimento das oficinas foi às situações inesperadas aos quais vivenciaram e tiveram que solucionar, já que atuaram na condição de professor. Outro ponto foi o apoio financeiro para a preparação de materiais didáticos, qualificando-os.

Quanto às dificuldades, o tempo para a preparação e execução das ações foi o fator mais limitante, segundo os acadêmicos. Outro aspecto, foi quanto ao ambiente de estudos, nota-se que a quantidade de alunos não condiz com a estrutura das salas. Assim como, a falta de intimidade com a turma da escola. Seria importante, uma aproximação de mais tempo com os alunos, esta interação poderia gerar mais empatia, fluindo melhor as ações.

Com as experiências vivenciadas pelos licenciando no decorrer das oficinas e analisando os comentários feitos por eles, observa-se também a satisfação no desenvolvimento das oficinas, que apesar das dificuldades encontradas também houve maior interação com a turma, sendo possível contribuir para a construção do conhecimento dos licenciandos.

\section{CONSIDERAÇÕES FINAIS}

Os avanços na formação de professores devem-se à reformulação das políticas educacionais como a LDB e as Diretrizes Nacionais, e mais recentemente, às políticas de fomento de formação como o PIBID e o Programa Novos Talentos. O PIBID tem se mostrado eficaz na aproximação entre universidade e escola, além de contribuir mais significativamente para produção de conhecimento por parte dos pibidianos, sejam esses conhecimentos científicos e próprios da ciência geográfica, como os conceitos norteadores, sejam de conhecimentos da prática pedagógica.

No caso particular do PIBID Geografia da UNICENTRO, isso fica evidente a partir dos dados da pesquisa, onde confrontados os dados obtidos com os pibidianos, com os demais acadêmicos não bolsistas. O programa também tem se mostrado 
eficaz como potencial transformador das instituições envolvidas no processo universidade e escola pública - criando um espaço privilegiado de formação e trabalho.

No âmbito dos Novos Talentos, também este programa tem potencializado as ações nos cursos de licenciatura, e no caso do projeto em análise, foi um importante articulador entre as ações do estágio supervisionado e o PIBID. Trata-se de um fomento voltado ao professor da escola, mas quanto articulado a formação inicial (estágio supervisionado) também tem trazido importantes resultados para as licenciaturas.

De modo geral, estes programas têm evidenciado a necessária necessidade de fomento ao ensino, agregado ao tempo e espaço para que a formação se realize integrando de forma salutar a universidade e a escola.

\section{REFERÊNCIAS}

AMBROSETTI, N. B., NASCIMENTO, M. C. A., ALMEIDA, A., CALIL, A. C., PASSOS, L. F. Contribuições do PIBID para a Formação inicial de professores: o olhar dos estudantes. Educação em Perspectiva, 2013, oํ 1, v. 4, jan/jun 2013. p.151-174.

AZEVEDO, R. O., GHEDIN, E., SILVA-FORSBERG, M. C., GONZAGA, A. M. Formação inicial de professores da educação básica no Brasil: trajetórias e perspectivas. Revista Diálogo Educação, 2012, no 37, v. 12, set/dez 2012. p. 9971026.

BRANDÃO, C. R. Repensando a Pesquisa Participante. São Paulo: Brasiliense, 1984.

BRASIL. Lei n. 9.394/96, de 20 de dezembro de 1996. Diário Oficial da República Federativa do Brasil, Poder Legislativo, Brasília, 23 de dezembro de 1996. Coordenação de Aperfeiçoamento de Pessoal de Nível Superior - CAPES.

Relatório de gestão da diretoria de formação de professores da educação básica 2009-2011. Disponível em: http://www.capes.gov.br/educacao-basica/capespibid. Acesso em 10 de julho de 2014.

Decreto n. 7.219 de 24 de junho de 2010. Diário Oficial da República Federativa do Brasil, poder legislativo, Brasília, 25 de junho de 2010.p. 04.

MELLO, G. N. Formação Inicial de Professores para a Educação Básica: uma (re) visão radical. São Paulo em Perspectiva. 2000. São Paulo, 14ª ed. v. 1. 2000. P. 98 110.

SANTOS, R. F. Pesquisa Participante: o que é e como se faz. Disponível em: http://baixadacarioca.wordpress.com/2012/03/19/pesquisa-participante-o-que-e-comose-faz/. Acessado em: 02 de novembro de 2013.

SARTORI, J. Formação de professores: conexões entre saberes da universidade e fazeres na educação básica. Anais de evento: formação de professores. Universidade federal do Rio Grande do Sul. Porto Alegre, 2011

\footnotetext{
${ }^{1}$ Michael Wellington Sene, Doutorando em Geografia pela Universidade Estadual do CentroOeste - UNICENTRO. Universidade Estadual do Centro-Oeste - Paraná - Brasil. Rua Simeão
} 
Camargo Varela de Sá, 03 - Vila Carli | CEP 85040-080 | Fone: (42) 3629-8100, Guarapuava PR.L E-mail: michael mws03@hotmail.com

${ }^{2}$ Marquiana de Freitas Vilas Boas Gomes, Professora do Departamento de Geografia e do Programa de Pós Graduação em Geografia da UNICENTRO. Universidade Estadual do Centro-Oeste - Paraná - Brasil. Rua Simeão Camargo Varela de Sá, 03 - Vila Carli | CEP 85040-080 | Fone: (42) 3629-8100, Guarapuava - PR. E-mail: marquiana@unicentro.br 